\title{
A CONTRIBUTION TO THE HISTOPATHOLOGY AND HISTOGENESIS OF SYRINGOMYELIA *
}

\author{
G. B. HASSIN, M.D. \\ Attending Neurologist, Cook County Hospital \\ CHICAGO
}

There still reigns a great confusion of opinions relative to the nature and origin of spinal cord cavities in general, and of those known as syringomyelia in particular. Thus, Schlesinger, ${ }^{1}$ after extremely detailed discussion (covering 140 pages) concerning the pathology and pathogenesis of syringomyelia, comes to the conclusion that it may be caused by many anatomically different processes, and offers the following anatomic classification of spinal cord cavities:

1. Cyst formations (caused by injuries of the spinal cord, i. e., traumatic, also nontraumatic hematomyelias).

2. Softenings of inflammatory and noninflammatory origin, with a short course of the morbid process.

3. "Syringomyelien," in the form of: (a) malformation; $(b)$ an actual tumor formation; $(c)$ syringomyelia gliosa; $(d)$ syringomyelia from vascular disorders without gliosis, and $(e)$ pachymeningitis and leptomeningitis combined with cavity formations.

Schlesinger thus accepts at least five types of syringomyelia, each type differing from the rest anatomically and pathologically. If such be the case, syringomyelia cannot be considered a specific morbid condition, and clinically should be looked on rather as a syndrome. Such a view is shared by practically the greatest majority of students of this disease. For instance, Thomas and Quercy ${ }^{2}$ claim that syringomyelia is devoid of any specific anatomopathologic features, and that it would be more proper to substitute the name of medullary cavities for that of syringomyelia, as, in their opinion, there are "syringomyelias" caused by gliomas, developmental anomalies, traumas, hematomyelias, softening, etc.

On the other hand, Phillippe and Oberthür ${ }^{3}$ would call the latter types rather pseudosyringomyelias, referring to syringomyelia proper

* From the pathology laboratories of Cook County and Psychopathic Hospitals of Chicago.

1. Schlesinger, H.: Die Syringomyelie, Ed. 2, Wien und Leipzig, 1902.

2. Thomas and Quercy: Syringomyélie, hyperplasie du tissue conjonctif, fibres musculaires striées dans la moelle, Nouv. iconog. de la Salpêtrière 25: 364, 1913.

3. Phillippe, C., and Oberthür, J.: Contributions à l'étude de syringomyélie et des autres affections cavitaires de la moelle épinière, Arch de méd. expér. et d'anat. path. 12:513, 1900. 


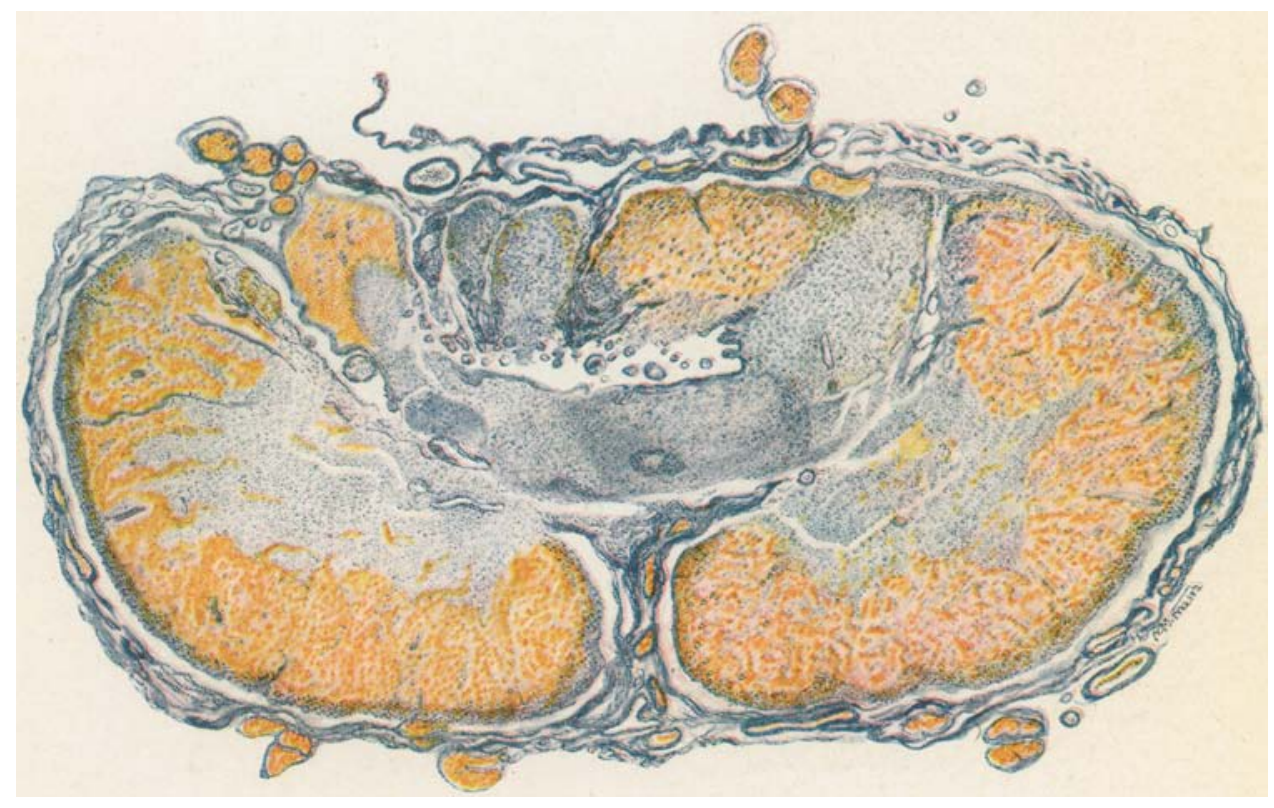

Fig. 9.-Syringomyelia; cervical enlargement. The pia, myelin, axons, gray matter, the pathologic glia, the marginal glia stained in different colors. Combined Bielschowsky-Alzheimer-Mann stain.

Illustrating Article by G. B. Hassin, M.D., 
only those morbid conditions that possess a certain specific pathology which they claim cannot be confounded with any other morbid condition. Though admitting two types of syringomyelia, cavitary and pachymeningitic, Phillippe and Oberthür believe that they are independent of each other, though caused by the same as yet unknown etiologic factor. The foregoing references represent prevailing opinions relative to the nature of syringomyelia. In spite of an enormous literature bearing on the subject, I believe my findings are of sufficient interest to be recorded.

From the study of my case, as well as from the most important previous contributions to this question, the conclusion may be drawn that in syringomyelia we do possess a number of specific pathologic changes which totally differ from those to be found in any other spinal cord lesion-changes which stamp syringomyelia as a distinct anatomopathologic entity.

\section{REPORT OF CASE}

History.-A white, married laborer, aged 54, entered Cook County Hospital, April 26, 1919, on the dermatologic service of Drs. Harris and Stillians, complaining of "sores" on the right arm and left shoulder. About three weeks previously his right arm felt lame, and showed a small, painless, red lump. Two weeks later this lump broke, discharging very foul-smelling pus. The sore on the left shoulder was also painless and of but two days' duration.

He had been a patient at the county hospital thirty-four years before for some trouble with the right eye, which was operated on, but he did not know the nature of the trouble. He had chancre twenty-five years before; and gonorrhea, twenty and two years before. He used to drink. His family history was of no importance.

Examination.-The patient was rather poorly nourished without any deformities, except an opacity over the right pupillary area and scars from an old iridectomy. On the right shoulder there was an ulcer, about $1 \frac{1 / 2}{2}$ inches in diameter, roughly circular, with a clear-cut margin; the edges were not thickened or everted, exposing the muscles beneath, which formed the floor of the ulcer; there was a scanty, yellowish discharge. The surrounding skin was reddened, scaling and, like the ulcer, painless. Lower down on the same arm, over the deltoid insertion, as well as over the left shoulder, similar ulcers were developing. The rest of the skin, on the back and lower limbs, was covered with "bites," scratch-marks and scars. Over the right hip was a discolored area. The muscles of the arms and both shoulders were atrophied.

Sensibility.-The temperature was abnormal. The pain sense was markedly impaired, the touch less so. The patient was rather indifferent to examination and cooperated poorly; yet it could be demonstrated that the entire surface of the body, including the upper and lower limbs, but excluding the face, was anesthetic, the anesthesia comprising the pain, temperature and touch senses.

Reflexes.-The pupillary (on the left) was sluggish; cremasteric and abdominal, normal; tendon reflexes, markedly exaggerated, with bilateral clonus, positive Babinski, Oppenheim, Gordon and Schaffer. The gait was uncertain, ataxic; the muscle power, greatly diminished. There were no tremors. The 
serologic examination gave a negative globulin, and a negative Wassermann test in both the blood and the spinal fluid, 20 cells per cubic milimeter and a negative Lange test (0011210000).

Course.-The ulcers grew larger, spreading over the scapulae, exposing the heads of the humeral bones and copiously discharging pus. Involuntaries (bladder and rectal) set in; the patient became totally paralyzed, apathetic, filthy. The tendon reflexes disappeared entirely; the sensory disorders became more marked, and two months after his entrance into the hospital he died.

Macroscopic Examination of the Spinal Cord and Meninges.-The dura was of normal thickness with smooth, shiny surfaces, without adhesions, pseudomembranes, hemorrhages, or any other pathologic deposits. The pia appeared thickened, especially around the cervicodorsal region and adherent to the spinal

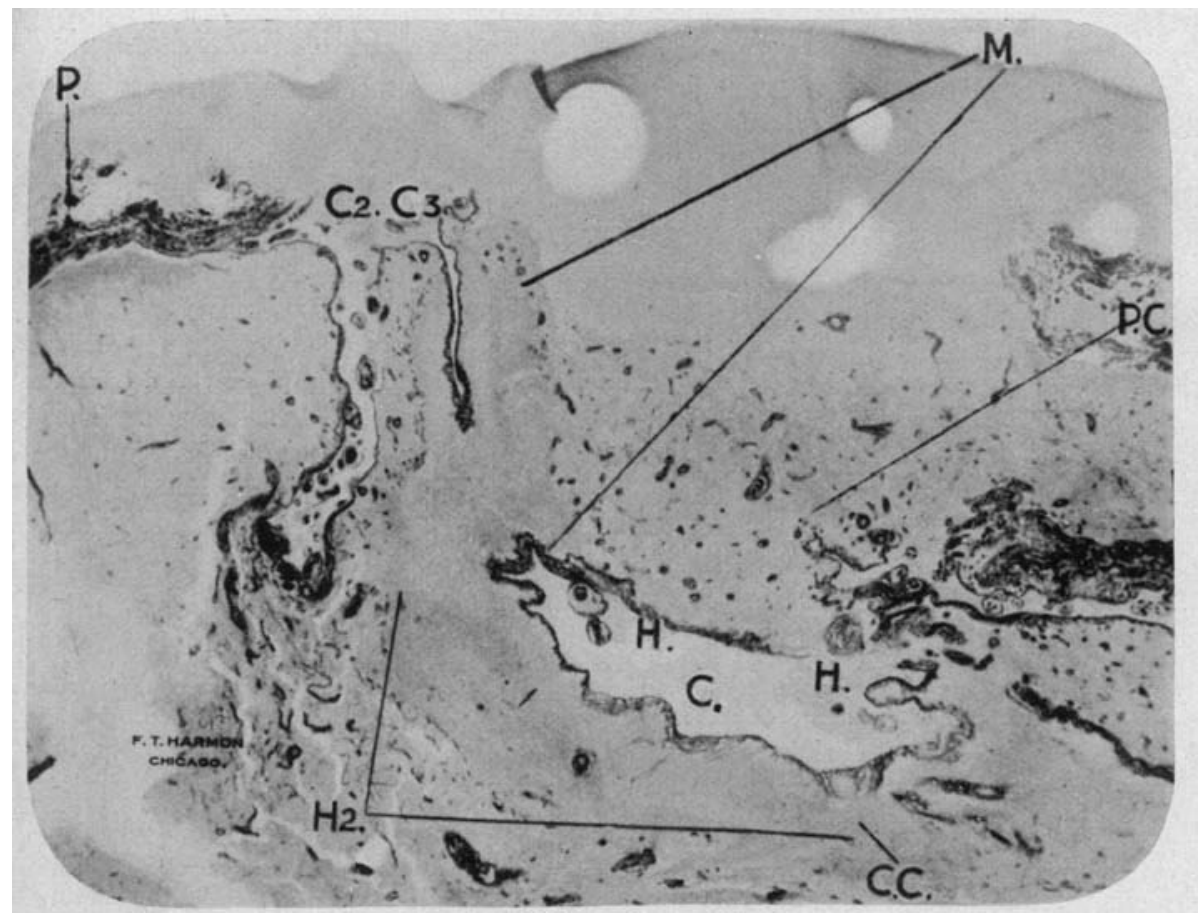

Fig. 1.-Syringomyelia cavities in the cervical cord enlargement. The main cavity (C.) contains patches of "homogenized" glia $(H . H$.$) and two vascular$ islands. The accessory cavities $\left(C_{2} C_{3}\right)$ distinctly show their membranes originating from the pia. $H_{*}$ is the zone of "hemogenization;" P.c., posterior columns; $M$., new forming membrane. Alzheimer-Mann stain; celloidin section $\times 20$.

cord. The latter was greatly flattened in the mid-dorsal region. In the cervical region, which was somewhat enlarged, there was a small cavity, surrounded by a gray area occupying both posterior horns and the greater part of the posterior columns. The upper half of the dorsal portion was very friable, granular in appearance and surrounded by remnants of white matter. The lumbosacral segments were of normal configuration, but on section exhibited 
a granular mass in the center, part of which dropped out. leaving irregularly shaped cavities. The lower lumbar region and the entire sacral region presented slightly disfigured posterior columns, being otherwise well preserved.

The medulla, midbrain and the hemispheres revealed nothing pathologic.

Microscopic Examination.-The changes found in the spinal cord in general may be classified as (1) cavities, (2) thickened or hyperplastic pia, (3) a superabundance of vessels and capillaries enclosed within islands, and (4) so-called zones of homogenization.

The cavities showed well only in the cervical region, where six of them could be easily made out. Figure 1 shows three of the cavities; the largest, oblong and very irregular in shape, occupying the middle of the section behind the central canal and lined by a thick connective tissue membrane. The acces-

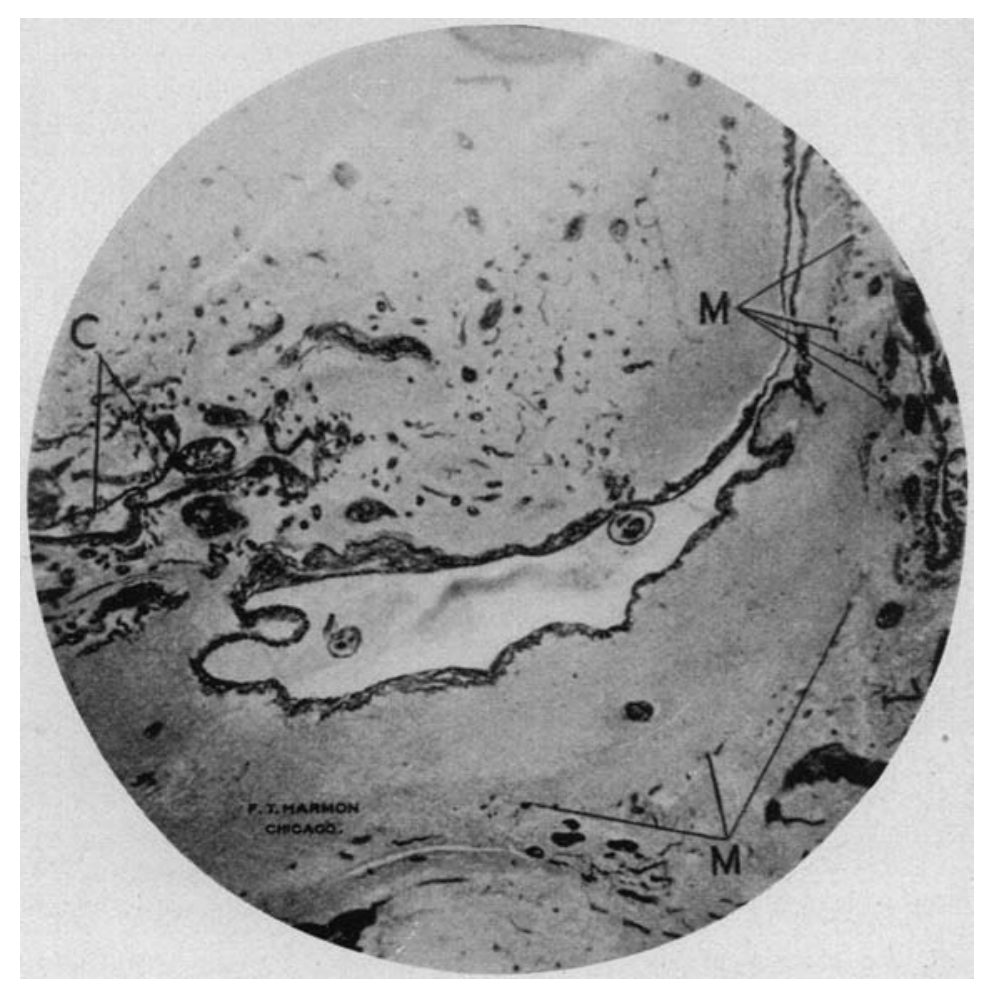

Fig. 2.-Part of the cervical enlargement of the spinal cord. The center is occupied by a large cavity lined by a collagenous connective tissue membrane. The larger portion of the cavity is filled with pale mass remnants of the homogeneous area surrounding the cavity and separated from the preserved parenchyma of the spinal cord by a thin irregular membrane, $M$. The upper left quadrant is covered with numerous vessels, vascular islands and remnants of a cavity, $C$., lined by a connective tissue membrane. Alzheimer-Mann stain; celloidin section, $\times 23$.

sory cavities, to the left of the larger one, communicate with each other and reach the periphery of the spinal cord, where detachments of the pia can be seen running along their edges and forming a lining. The other three cavities, 
not shown in the picture, occupy the right portion of the posterior columns and the right posterior horn. Each cavity contained a powerful connective tissue membrane which did not show any epithelial lining, but was studded in some places with a great amount of vessels (Fig. 1, $C_{2}$ ). The cavities were separated from each other by a homogeneous substance, a pathologic glia, which was also present within the cavities themselves (Figs, 1 and 2). All the cavities ended blindly in the spinal cord and were in no way connected with the central canal, but communicated with the inner surface of the pia. Those portions of the posterior columns which were not taken up by the cavities were converted into a homogeneous mass (Figs. 1 and 2). The anterior horns were cut off by the latter, leaving intact the anterior portion, which was

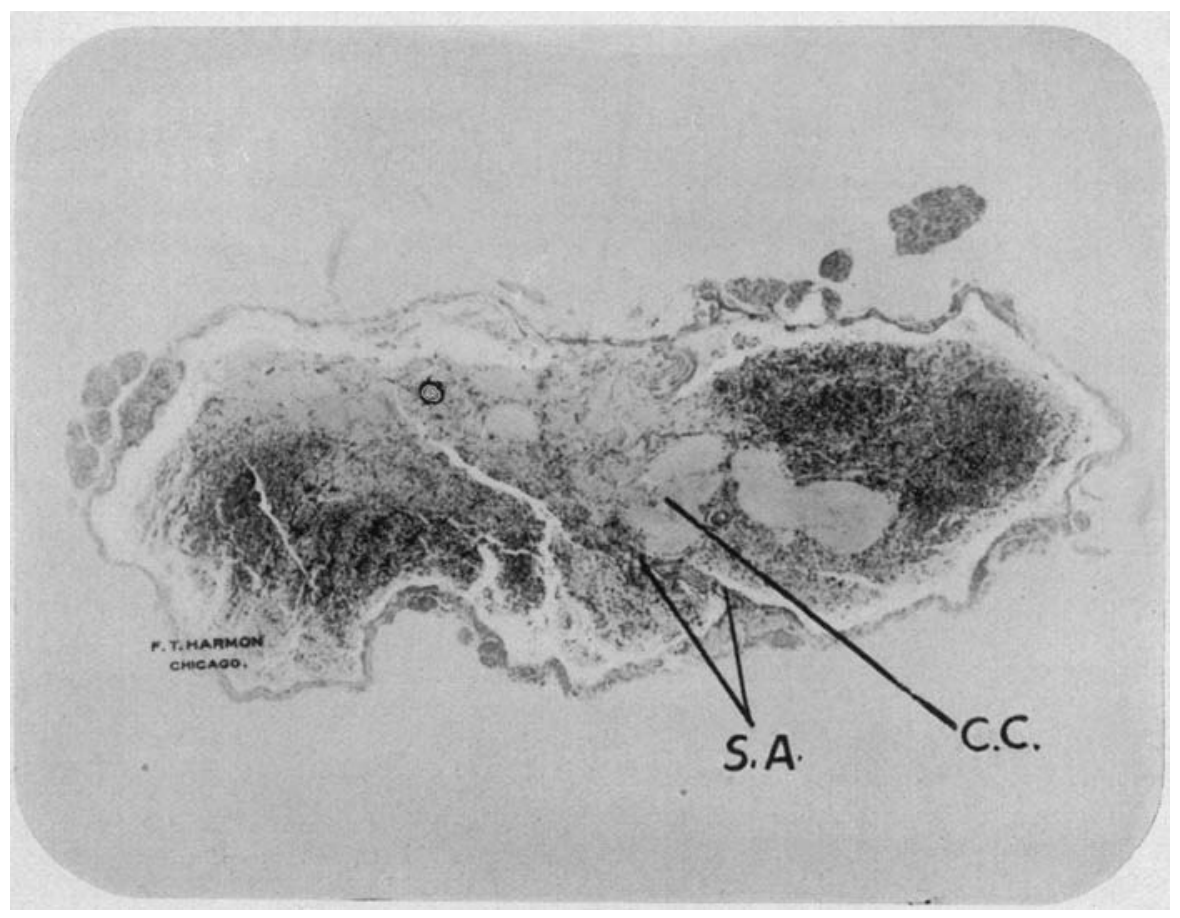

Fig. 3.-Dorsal segment in a case of syringomyelia. The thickened pia is torn off, the parenchyma is collapsed and disfigured. S.A., anterior fissure filled with a thickened pia; C.C., central canal. The lateral columns are well preserved; the broken down posterior half of the spinal cord contains pale islands of pathologic glia. Combined Weigert Pal-Van Gieson stain, $\times 11$.

exceedingly vascular. The lateral and anterior, as well as the undamaged portions of the posterior columns, were more or less well preserved; but many nerve fibers in them were replaced by glia tissue which was much more abundant than in a normal cord. In the dorsal, lumbar and sacral portions there were no real cavities, the empty spaces to be encountered there being due to the falling out of the friable mass. The photomicrograph (Fig. 3) gives some idea of the changes in the dorsal region which was disfigured and collapsed. The lateral and anterior columns were somewhat preserved, 
while in the lumbar region (Fig. 4) the posterior columns showed an abundance of connective tissue strands, the subpial marginal glia zone being totally obliterated and the edge of the white matter depressed. Other sections of the dorsal region, partially reproduced in Figure 5, appeared uniform, were granular, and were occupied in some places by connective tissue fibers forming so-called islands. The tissue was very unstable, was friable, and was very losely held together, as if being prevented from falling apart by the surrounding powerful pia. Some portions of the spinal cord sulbstance were missing, and an empty space was plainly in evidence.

In contrast to marked degeneration of the cord sulstance, the pia was remarkably developed. All along the spinal cord, especially in the cervicodorsal region, this membrane was greatly thickened. It gave a lining to the cavities (Fig. 2), even obliterating some of them and appearing distinctly

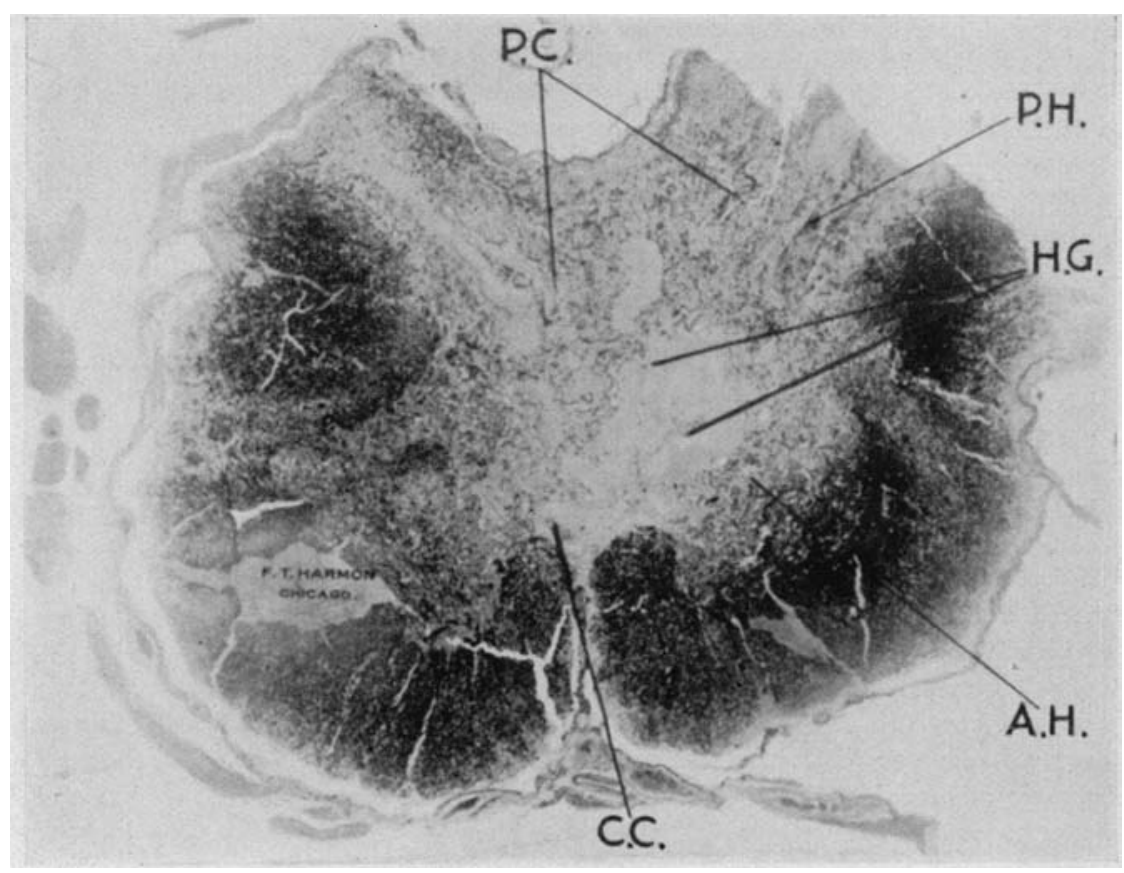

Fig. 4.-Lumbosacral region; the thickened pia forms in the posterior columns a marked concavity; the anterior and lateral columns are well preserved. C.C., central canal; A.H., anterior horn cut off from the posterior horn, P.H., by a mass of homogeneous glia, $H . g$. Weigert-Pal stain counterstained with Van Gieson, $\times 11$.

fibrillar. In thin sections the pia fibers showed no nuclei, but a thicker section showed that the latter could be detected in the form of large spindle-shaped bodies with rounded edges, filled with chromatin granules. Young connective tissue cells, fibroblasts, perivascular infiltrations, plasma cells, lymphocytes, pigment deposits or hemorrhages were totally absent in the pia. The pia entirely enveloped the spinal cord, carrying a great number of hyperemic veins and capillaries. It invaded the spinal cord substance in the form of bands, and 
was closely adherent to the subpial glial tissue, but did not press on the posterior or anterior roots. We have here a hyperplastic pia, which, like a fibrous ring, surrounds the spinal cord, especially in places of its greatest destruction (cervicodorsal portions). The outlined features can very well be followed up with Van Gieson, Mallory-Jakob, Alzheimer-Mann, or light-greenfuchsin stains, but especially well with the combined Bielschowsky-Alzheimer method which will be described in detail at the end of this paper.

The vessels were exceedingly numerous in both gray and white substances, in the normal as well as in the pathologic areas. The homogeneous zone surrounding the cavity was rather poor in vessels, but the membrane lining the cavity was as a rule enormously vascularized (Figs. 1 and 6). Yet, even with Weigert's elastic stain, signs of vascular proliferation could not be found. Nor could any signs of inflammation be found, like perivascular infiltrations, distention of Robin-Virchow's lymph spaces in the adventitia, or any intima changes. The lumen was almost always open, containing some red cells, and was narrowed because of the greatly proliferated adventitia. This uniformly showed several layers of connective tissue fibers with few or no nuclei, staining very readily with Van Gieson, Alzheimer-Mann, Jakob-Mallory, and still better with a combined Bielschowsky-Alzheimer-Mann stain. With all these stains it was possible to demonstrate the hyperplastic state of the adventitia in every vessel and capillary to be found in the pathologic area. In the preserved portions of the anterior horns, and lateral and anterior columns, the vessels were hyperemic and in some places were surrounded by a thickened prolongation of the pia, but did not show hyperplastic adventitia. In some regions of the spinal cord, especially the gray matter and around the membranes of the cavities, the vessels, however small, were surrounded by connective tissue rings forming round or oval islands of various sizes. These are the so-called "encapsulations" of Petren (Figs. 5 and 6), already pictured by Lockhart Clarke. ${ }^{5}$ These islands or encapsulations sometimes contain several small vessels or capillaries with thickened adventitial walls, consisting, like the other vessels, of hyperplastic connective tissue. The islands were areolar in structure (Fig. 5), and consisted of meshes of glia fibers which were either empty or contained remnants of broken up glia tissue (nuclei, cell bodies and fragments of fibers). In some places the islands showed several concentric rings, or an island came into view that contained several separate rings, these being smaller vessels enveloped by a thick hyperplastic adventitia (Fig. 6). Such sclerosed vessels surrounded by one common capsule were described by Thomas-Hauser" as "formations conjonctivovasculaires," and by Cerletti "vascular aggregations." Petren calls them vascular islands which he asserts originate from the encapsulations. The capsule comes, he thinks, from the bands of connective tissue invading the posterior horns. They grow so large that for lack of space they have to fold, enveloping portions of gray matter and forming rings enclosing gray matter.

4. Petren, Carl: Beiträge zur pathologische Anatomie und zur Pathogenese der Syringomyelie und der Syringobulbie, Virchows Arch. f. path. anat. 196: $377,1909$.

5. Clarke, J. Lockhart: On the Pathology of Tetanus, Med. Chir. Trans. 48:255, 1865; Pathologic Investigations in a Case of Paraplegia, Brit. and Foreign Med. Chir. Rev. 33:485, 1864.

6. Cerletti, Ugo: Die Gefässvermehrung im Zentralnervensystem; Niss1Alzheimer's Arb. 3:1, 1911. 
When the latter is absorbed, a vascular island remains. Instead of nerve tissue, we have, then, connective bands and sclerosed vessels-a scar as it were -representing the ultimate healing process of the diseased spinal cord tissue. On the other hand, this connective tissue proliferation accompanied by vascular sclerosis may appear as a forerunner of a progressively developing cavity, acting as a "destructive" agent. The destructive stage is followed by a "constructive," progressing, healing process which takes place after the parenchyma has been destroyed. The connective tissue proliferation is, according to Petren, a chronic inflammation which results in the formation of numerous sclerosed vessels. Such cases Petren calls sclerotic syringomyelia in distinction from the glial type (syringomyelia gliosa) which is due to hyperplasia of the glia. The sclerotic type of syringomyelia rums a shorter clinical

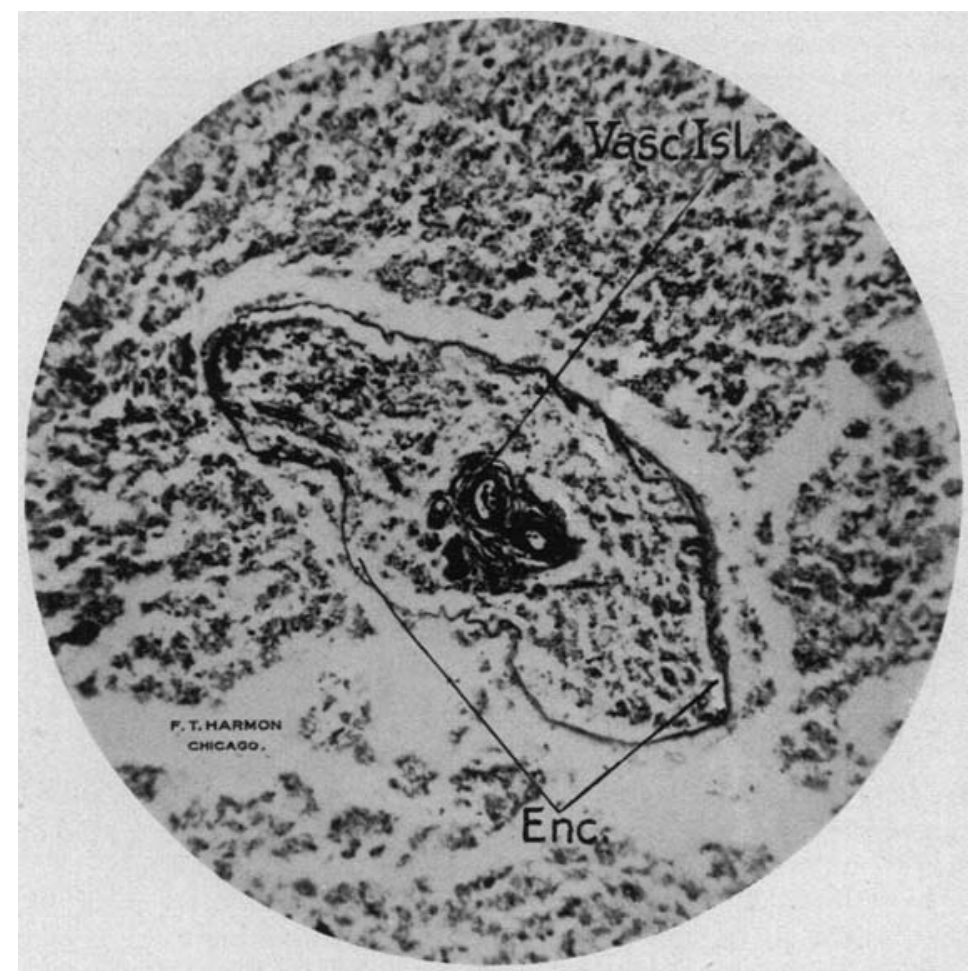

Fig. 5.-Lower dorsal region; the upper portion is granular; the lower, greatly rarefied and in some places devoid of substance. The black dots are cross sections of axons; the paler subtsance is glia tissue. The middle of the illustration is occupied by an "encapsulation" (Enc.), the membrane of which is separated from the vascular island (Vasc. Isl.) by decomposed glia tissue and remnants of nerve fibers. Bielschowsky stain; paraffin section, $\times 100$.

course; the latter, a more protracted one. Such are some of the conclusions Petren arrived at from the study of connective tissue bands, connective tissue islands and encapsulations.

As these three types were represented in my case, Petren's interpretations are not in complete accord with my findings. The photomicrographs show 
the connective tissue formations are present only in those places where there are to be found remnants of a substance described under various names (couches scleroses by Hallopeau. ${ }^{7}$ colloid substance by Roth, ${ }^{8}$ "Gewebsmasse" by Chiari," homogeneous sulstance by Schwarz" "homogenization" zone by Schlesinger, ${ }^{1}$ primitive gliosis by Phillippe and Oberthür $\left.{ }^{3}\right)$. This substance is especially marked in Photomicrograph 2 in the shape of a broad mass surrounding the membrane. This mass can be found within the cavity itself as a patch sticking to the wall, or between two adjacent membranes (Fig. 1) or within the meshes of the latter, but is never found beyond the outer wall of the membrane. The latter thus cuts the glia or the parenchyma into two parts, the inner part, pathologic; the outer, normal.

The microscopic examination of the homogeneous masses showed a network of delicate glia fibers, with a number of small glia nuclei more or less well preserved, though some stained rather badly. Quite often there was but a remnant or a fragment of a glia reticulum with a great mass of uniformly stained, usually pale, round bodies of various sizes. Some of them gave a perfect reaction for amyloid, and there can be no question that many of these round or oval formations were amyloid bodies. Mixed with the latter, there were other spheroid bodies of almost similar size, equally stainable with various anilin dyes, but containing a very small, shrunken nucleus, apparently collapsed, always located at the very periphery of the cell body, as if ready to leave it (Fig. 7). In some such cells half of the nucleus could be seen as if sticking out of the cytoplasm, and some cells were encountered without any nucleus whatever. Such cells greatly resemble amyloid bodies, from which they differ by failing to show the iodin reaction. It is probable that some such cells ultimately become actual amyloid bodies, in accordance with the views of Fromman, Obersteiner, Redlich ${ }^{11}$ and others who consider them as the products or modifications of glia. In addition, there is in the homogeneous substance a third variety of spherical globules, very numerous and much smaller and paler, appearing as fine, minute droplets. They are especially numerous within the cavities, in the walled-off, or as Thomas and Hauser $^{12}$ express it, in the areas "parceled out" by connective tissue bands and vessels. They are also to be found in great masses within the connective tissue spaces, in the adventitial walls, in the encapsulations or islands, in the pia meshes, in short, wherever the glia is destroyed or damaged. One gains the impression that the proliferating connective tissue in spreading to the periphery envelops them as a useless substance, before they finally perish and become absorbed. The remarkable feature is that even in these greatly changed patches of glia tissue, there may be found well preserved nerve fibers, or,

7. Hallopeau, H.: Contributions à l'étude de la sclérose diffuse péri-ependymaire, Soc. de Biologie, Ser. 5, 21:169, 1869.

8. Roth, W.: Gliome diffuse de la moelle, syringomyélie, atrophie musculaire, Arch. de physiol. normale et pathol. 10:612, 1878.

9. Chiari.: Ueber die Pathogenese der sogenanten Syringomyelie, Ztschr. f. Heilk. 9:307, 1888.

10. Schwarz: Ein Fall von Meningo-myelitis Syphilitica mit Höhlenbildung im Rückenmark, Ztschr. f. klin. Med. 34:467, 1898.

11. Redlich, E.: Die Amyloidkörperchen des Nervensystems, Jahrl. f. Psychiat. u. Neurol. 10:1, 1891.

12. Thomas, A., and Hauser, G.: Histologie pathologique et pathogénie de la syringomyélie, Nouv. iconogr. de la Salpêtrière 17:376, 1904. 
what is more frequent, fragments of well-stained myelin and axons. These changes in the "homogenized" area can be much better followed up in longitudinal section (Fig. 7). The photomicrograph distinctly shows the nerve fibers, enlarged or ampule-like, in some instances thinned, of distinct fibrillary structure and staining well. In some fibers the axon is plainly visible; in others, it is masked by a powerful myelin sheath forming basket-like enlargements connected with each other by thin strands of fibrils. The spaces between adjacent fibers is occupied by the round bodies and spherules described above, the entire mass resembling Alzheimer's "Füllkörperchen" and his ameboid glia. Places less damaged or not much disintegrated show a few poorly stained gitter-cells, large protoplasm-rich glia cells uniformly stained, with an eccentric

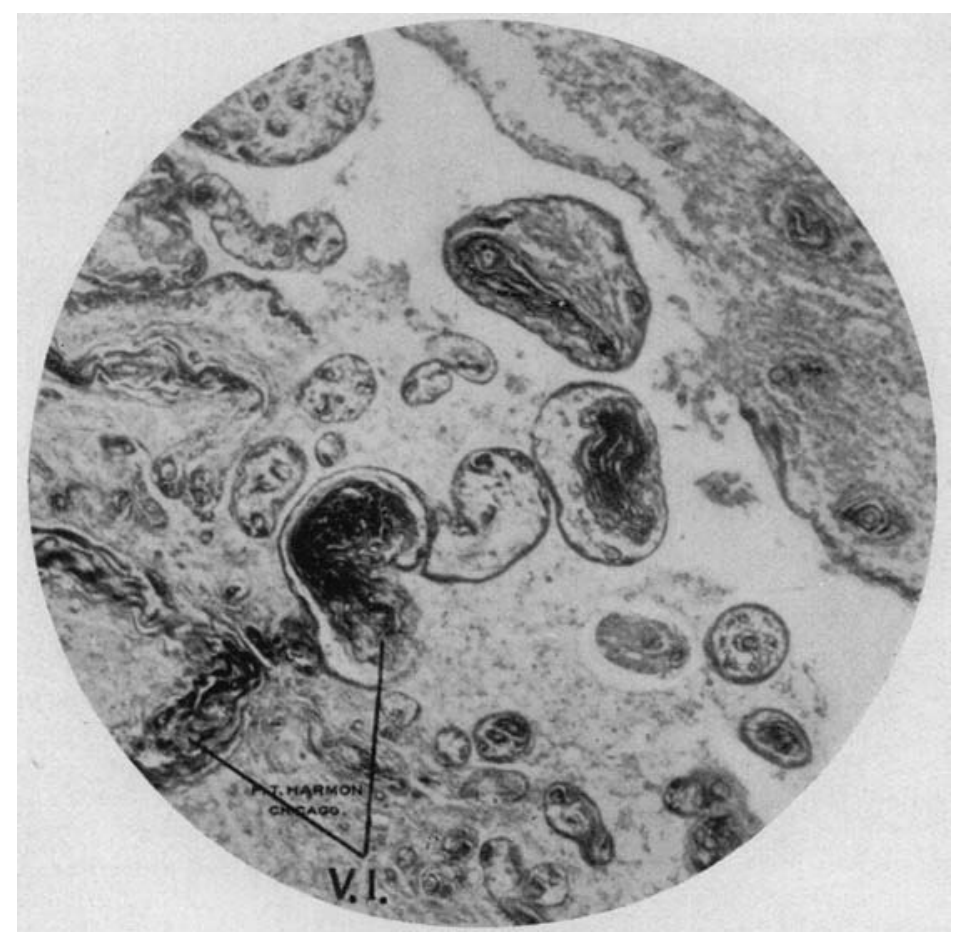

Fig. 6.- Vascular islands, V.I.; the rest of the round formations are encapsulations, some inclosing longitudinaily cut vessels: from an area near the cavity. Combined Bielschowsky-Alzheimer-Mann stain; paraffin section, $\times 85$.

nucleus, and occasionally even so-called myelophages. Herxleimer stain, whi:h was hard to carry out on account of the difficulty of obtaining proper frozen sections of a friable granular mass, showed the presence of fat globules.

The central canal was found occluded by a mass of proliferated cells, nowhere connected with the cavities, and surrounded by a homogeneous mass which microscopically (Fig. 8) appeared to consist of a delicate glia reticulum containing a number of glia nuclei. It somewhat resembled the structure of the "homogenization" zone, but the process evidently had not progressed very far. The lateral and anterior columns and the preserved gray matter of the 
anterior horns showed no gross abnormalities, like ganglion cell changes, secondary degenerations, etc. The medulla and cortex exhibited vascular changes only. In the former, some vessels were slightly infiltrated with lymphocytes. In the cortex there was marked proliferation of capillaries, without any other changes, like infiltrations, ganglion, glia or meningeal changes. Pathologic changes were exclusively confined to the spinal cord, being at some levels more pronounced, at others less, confined principally to the glia, the vessels and pia, with or without cavity formation. It is obvious that the latter is not an essential factor in syringomyelia, as many levels in this case did not show cavities at all. Prolsably they would have formed had the patient lived

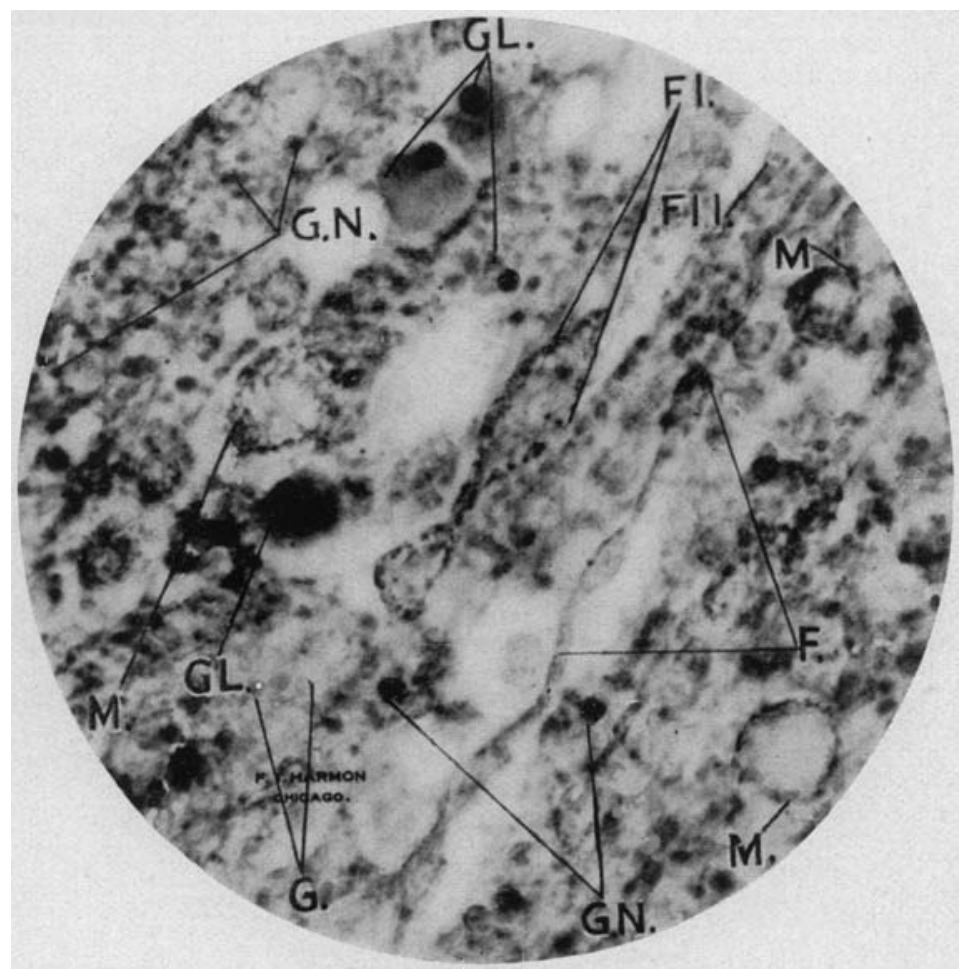

Fig. 7.-Longitudinal section of the "zone of homogenization." G.n., glia nuclei; $G l$, glia cells with picnotic nuclei about to desert the homogeneous cell bodies; $M$, myelin; $F i$, nerve fiber with granular ampular enlargements of the myelin sheath; $F$ and $F i i$ comparatively less changed nerve fibers; $G$, sale glia cells resembling amyloid bodies. Combined Bielschowsky-Alzheimer-Mann stain. $\times 700$.

longer; that is, the changed areas which appeared as homogeneous zones would ultimately have become transformed into cavities.

Of the five factors (changes in the pia, the vessels, areas of homogenization, island and membrane formation (Petren's encapsulations), the most important, the primary factor, is change in the glia. But the character and nature of these glia changes are quite different from those to be found in 
various other spinal cord lesions, like multiple sclerosis, secondary degenerations, myelitis, amyotrophic lateral sclerosis and subacute combined cord degeneration, in which glia changes are also the dominant feature. For in syringoinyelia the glia does not show the exquisite progressive or proliferative properties so pronounced in the former diseases, nor the equally exquisite regressive character seen in myelitis. It is true that in syringomyelia there may be encountered some signs of a proliferative nature, represented by a few gitter-cells, fat globules, few myelophages, and large protoplasmic glia cells; but these signs are so insignificant, so scarce, and so overshadowed by the opposite phenomena of retrogressive character, outlined above, that at least in this case we cannot speak of a proliferation of glia.

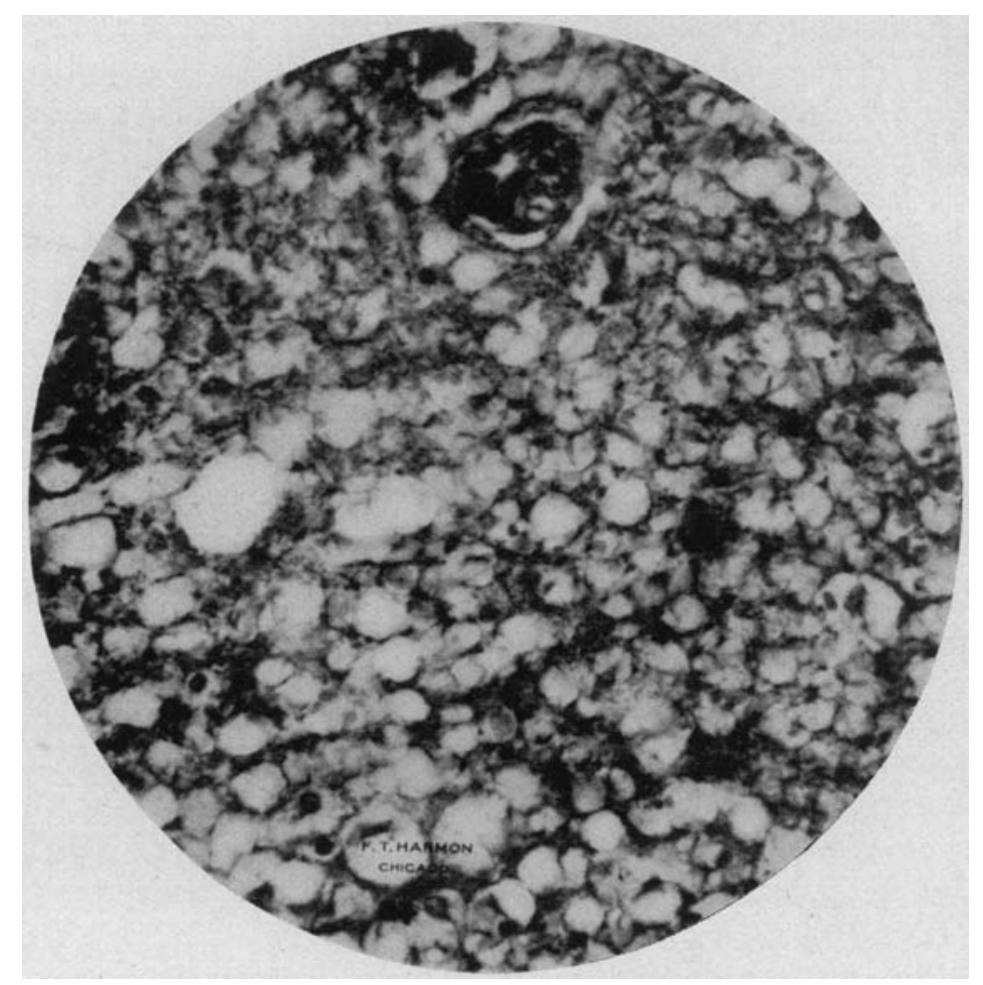

Fig. 8.-An area from the posterior commissure consisting of a glia reticulum, glia nuclei (black dots) and an aggregation of vessels (in the upper portion of the illustration). Combined Bielschowsky-Alzheimer-Mann stain; paraffin section, $\times 450$.

On the contrary, the glia is rather regressive in character, especially near the cavities where the process must be assumed to be greatly advanced, while in the lower dorsal regions the morbid process is evidently of more recent date, no cavity formation being present. Furthermore, if glia tissue does proliferate, as in multiple sclerosis, subacute combined degeneration or secondary degenerations caused hy cerebral lesions (capsular or encephalitic lesions), the proliferation obtains at the expense of destroyed nerve tissue. The latter, 
however, is in syringomyelia, as shown by my case, not degenerated. Even in the most damaged areas, like the interior of the cavities themselves, nerve fiber fragments with their myelin and axon can be seen comparatively undamaged; that is, not enveloped by the glia cells, nor converted into lipoid substances, harbored by numerous and various gitter-cells, as is the case when the glia undergoes real proliferation. Nor are the glia changes in syringomyelia of the type seen in myelitis, for instance, where it assumes the ameboid features.

\section{COMMENT}

Evidently the syringomyelic changes of glia are altogether different from those to be found in progressive or regressive states, a fact already noted by Schultze $^{13}$ in 1882, when he coined for these glia changes in syringomyelia a new name, that of gliosis. Ten years later, Hoffman $^{14}$ called it primary, central, gliosis. To make clear the meaning of gliosis, Schultze defined it as the mildest or milder stage of glioma formation, as the forerunner of gliosis. In a later publication ${ }^{15}$ he compared its relationship to glioma as that of "a hill to a mountain." Bernstein and Horwith ${ }^{16}$ express themselves still more indefinitely. "There are seen," they say, "areas of gliosis which perhaps may bear toward the tissue we call glioma a relation similar to that which a fibroma bears to sarcoma (leaving out of consideration the question of malignancy)." Thus, according to Schultze and others, the proliferated glia in syringomyelia is different from a proliferated glia in other spinal cord diseases. If glia proliferates and breaks down it is called gliosis; if it proliferates and does not break down (multiple sclerosis, for instance) then it is not a gliosis. According to modern neuropathologic research, such a distinction between the two types of a proliferative glia is wholly untenable; in fact, it is incomprehensible. From Schultze's publications and his numerous followers (Miura, ${ }^{17}$ for instance) the sole outstanding, undoubted fact remains that in syringomyelia we have to deal with a primary lesion of glia, either around the central canal, or in Rolando's substance, or in some other part of the spinal cord. This fact is absolutely established, and we therefore must come to the conclusion that syringomyelia is essentially a disease of the glia and not of the nerve tissue, like multiple sclerosis,

13. Schultze, L.: Beiträge zur Pathologie und pathologische Anatomie des centralen Nervensystems, Virchows Arch. f. path. Anat. 87:510, 1882.

14. Hoffman, J.: Zur Lehre von der Lehre von der Syringomyelie, Deutsch. Ztschr. f. Nervenh. 3:1, 1892.

15. Schultze, F.: Die Pathogenese der Syringomyelie, Compt. rend. du $12 \mathrm{me}$ Congrés Int. de Med. à Moscou 4:265, 1897.

16. Bernstein, E. P., and Horwith, S: Syringomyelia with Pathological Findings, Med. Rec. 84:698, 1913.

17. Miura, K.: Ueber Gliom des Rückenmarks und Syringomyelie, Beit. z. path. Anat. u. z. allg. Path. (Ziegler's Beitr.) 11:91, 1892. 
amyotrophic lateral sclerosis, subacute combined degeneration, etc., which are essentially parenchymatous nerve lesions, in which the glia is secondarily involved.

The glia changes must necessarily be exceedingly chronic in course, as many cases last from forty to fifty years. In fact, the beginning of the trouble can never be definitely asserted, as the patient seeks advice only when he is much discomforted by some motor, trophic or other disturbance, and may go around for years without complaining, yet harboring the disease. This was probably the case with my patient, who gave a history of but three weeks' duration, and for some symptoms, two days. The deepest and most advanced destruction was in the dorsal spinal cord which suggests the possibility of his having some objective sensory disturbances on the trunk, chest, lumbar region, etc., which did not trouble him in any way until they became complicated by trophic lesions and forced him to go to the hospital. The process in every case must be much older than the date of the patient's first complaints, probably extending, as Saxer ${ }^{18}$ justly remarks, to the embryonal state, and probably being inborn. In other words, a person suffering from syringomyelia is probably born with a deficient glia, just as a person with progressive muscular atrophy or dystrophy is born with deficient ganglion cells or deficient muscle fibers; in both we have to deal with a developmental defect, an abiotrophy. The abiotrophy, in the former, shows itself in glia cells; in the latter, in the nerve or muscle cells.

As in the latter a great many ganglion cells are usually undamaged, appearing healthy, so in the former (syringomyelia) a great many glia cells may escape destruction and may even exhibit signs of increased activity, in the form of a rich cytoplasm, formation of myelophages, gitter-cells, etc. As in progressive muscular atrophy, in which the deficient ganglion cells may be confined to certain levels or segments of the spinal cord, the cervical region, for instance, in syringomyelia, the deficient glia also may be confined to a certain level, sparing the rest. When the deficient glia finally breaks down, disintegrates, it becomes a useless foreign body, which like any other foreign body becomes enveloped or walled off by connective tissue. The connective tissue proliferation is thus, contrary to the assertions of Hauser, Sterling ${ }^{19}$ and others, a secondary process, obtaining only when glia destruction is at its maximum, originating, as my case shows, in the pia and partly from the vessels. It is of hyperplastic, prolifera-

18. Saxer, F.: Beit. z. path. Anat. u. z. allg. Path. (Ziegler's Beitr.) 32: 276, 1902.

19. Sterling, W.: Beiträge zur Lehre von der Morvanschen Krankheit, Ztschr. f. klin. Med. 56:474, 1905. 
tive, not inflammatory character, and may be looked on as a natural reaction to the pathologic process displayed in the cavity. The latter is filled with fluid, and is usually greatly distended, the distention of course affecting the pia greatly.

I had an opportunity to witness such a distention during an operation (by Dr. Karl Meyer) on a patient with syringomyelia symptoms, which I had reason to believe were probably due to an intraspinal tumor. On opening the dura in the lower cervical region, the cord appeared distended, sausage-like, very pale, and without any signs of pulsation. When the posterior columns were incised, fluid came out with great force; the spinal cord collapsed at once, became hyperemic, and immediately showed active pulsations. The enormous pressure sustained by the cord in syringomyelia must be counterbalanced by the surrounding meninges, especially the pia, which is called on to hold the fluid and the remnants of the broken up cord firmly together, the hyperplasia being the ultimate result of this increased function. The same is true of the blood vessels, the adventitial walls of which are always greatly thickened, hyperplastic, thus protecting them from a too increased pressure and a probable total occlusion. This vascular state is absolutely pathognomonic of syringomyelia, as in no other pathologic state could $I$ see anything like it, and it is also pointed out without exception in every description of syringomyelia. Very often the sclerosed vessel is the center of various islands, encapsulations, which, as I have already stated, resemble in their structure, mode of growth, etc., the "homogenization" zone around the cavity.

If the glia is deficient from earliest life, then apparently normal spinal cords must be met which would show an abnormal glia state in the vicinity of the central canal or in the posterior horns, the usual seats of syringomyelia. This is actually the fact. Thus Schlesinger and Obersteiner ${ }^{20}$ saw many spinal cords, otherwise normal, showing a wider and larger posterior commissure, protruding into the posterior columns in the form of bands or massive processes and consisting of glia meshes, vessels and even occasional areas of homogenization or of fully developed gliosis. Zappert ${ }^{21}$ found in a spinal cord of a 19-months-old child a dilated spinal canal, glia proliferation, in which a homogeneous zone surrounded the central canal. These facts demonstrate the correctness of the assumption that syringomyelia dates back to the earliest days of existence and may run through the entire life unobserved or undiscovered; in short, that syringomyelia is a developmental anomaly. But this developmental anomaly does not pertain

20. Schlesinger, H.: Die Syringomyelie, Ed. 2, 1902, p. 324.

21. Zappert, J.: Kinderrückenmark und Syringomyelie, Wien. klin. Wchnschr. 14:949, 1901. 
to a patent central canal (Virchow, ${ }^{22}$ Leyden $^{23}$ ) or to a broken down tumor (Simon, ${ }^{24}$ Westphal ${ }^{25}$ ) or to slumbering epithelial cells around a maloccluded central canal which suddenly wake up and proliferate $\left(\right.$ Hoffman $\left.^{14}\right)$, or to a proliferation and subsequent breaking down of glia cells (Schultze ${ }^{\mathbf{1 3}}{ }^{15}$ ), but pertains to the inborn deficiency of glia tissue as outlined above. Nor has syringomyelia anything to do with traumatic and nontraumatic hematomyelias (Minor, ${ }^{26}$ Pitres and Sabrazes ${ }^{27}$ ), myelitis (Hallopeau, ${ }^{7}$ Joffroy-Achard ${ }^{28}$ ), pachymeningitis or leptomeningitis (Rosenblath ${ }^{29}$ ), all these morbid conditions having been advocated as the possible causes of syringomyelia. They all may produce cavities in the spinal cord, but not syringomyelia, which differs from the enumerated morbid states anatomically and histologically. Only those spinal cavities should be referred to as syringomyelia which exhibit glia or other changes as represented, in part, by the appended photomicrographs.

\section{STAINING METHODS}

The staining methods must necessarily vary according to the variety of tissues encountered in this case; axons, myelin, glia tissue, gray matter, vessels and pia. Of the numerous methods used, the most reliable and satisfactory one proved to be that of Bielschowsky counterstained with Mann's mixture (methyl blue-eosin). I had used it very succesfully on frozen sections in my studies of subacute combined cord.degenerations, ${ }^{30}$ while in this case frozen sections could not be used very well on account of the great disintegration of the tissues. I was therefore compelled to use paraffin sections of tissues that were fixed in chrom-fluorine and potassium bichromate (Weigert's

22. Virchow, R.: Die Betheiligung des Rückenmarks an der Spina Bifida und die Hydromyelie, Virchows Arch. f. path. Anat. 27:575, 1863.

23. Leyden, E.: Klinik der Rückenmarkskrankheiten, 2:447, 1875.

24. Simon, T.: Beiträge zur Pathologie und pathologische Anatomie des Centralnervensystems, Arch. f. Psychiat. 5:108, 1875.

25. Westpha1, C.: Ueber einen Fall von Höhlen-und-Geschwulstbildung im Rückenmark mit Erkrankung des verlängerten Markes, Arch. f. Psychiat. 5: 90,1875 .

26. Minor, L.: Zur Lehre von der Syringomyelie, Ztschr. f. klin. Med. 34: 373, 1898.

27. Pitres and Sabrazès: Contributions a l'étude clinique et anatomie pathologique de l'hematomyélie centrale, Compt. rend. du Congrés Int. à Moscou 1:292, 1897.

28. Joffroy, A., and Achard: De la myélite cavitaire, Arch. de Physiol. normale et pathol. 10:435, 1887.

29. Rosenblath, W.: Zur Casuistik der Syringomyelie und Pachymeningitis cervicalis hypertrophica, Deutsch. Arch. für klin. Med. 51:210, 1893.

30. Hassin, G. B.: Histologic findings in two cases of subacute combined cord degeneration, Med. Rec. 91:885, 1917. 
mordant fluid): After removal of paraffin the sections are stained with Bielschowsky's method in the usual manner. Without being impregnated with gold they are counterstained with Alzheimer-Mann ( 1 per cent. phospho-molybdic acid) for one hour, followed, after the sections are twice washed in distilled water, by methyl-blue-eosin for one half hour or longer. The pictures are strikingly beautiful, the connective tissue, the glia, the axons, myelin, the gray matter, all staining in different colors as shown in the appended colored reproduction.

31 North State Street. 